\title{
Effect of Alcohol Structure on the Optimum Condition for Novozym 435-Catalyzed Synthesis of Adipate Esters
}

\author{
Mohd Basyaruddin Abdul Rahman, ${ }^{1,2}$ Naz Chaibakhsh, ${ }^{1}$ and Mahiran Basri ${ }^{1}$ \\ ${ }^{1}$ Department of Chemistry, Faculty of Science, Universiti Putra Malaysia, 43400 Serdang, Malaysia \\ ${ }^{2}$ Structural Biology Research Center, Malaysia Genome Institute, MTDC-UKM, Smart Technology Centre, UKM Bangi, \\ 43600 Bangi, Selangor, Malaysia
}

Correspondence should be addressed to Mohd Basyaruddin Abdul Rahman, basya@science.upm.edu.my

Received 9 June 2011; Accepted 20 September 2011

Academic Editor: Shengwu Ma

Copyright ( 2011 Mohd Basyaruddin Abdul Rahman et al. This is an open access article distributed under the Creative Commons Attribution License, which permits unrestricted use, distribution, and reproduction in any medium, provided the original work is properly cited.

Immobilized Candida antarctica lipase B, Novozym 435, was used as the biocatalyst in the esterification of adipic acid with four different isomers of butanol (n-butanol, sec-butanol, iso-butanol, and tert-butanol). Optimum conditions for the synthesis of adipate esters were obtained using response surface methodology approach with a four-factor-five-level central composite design concerning important reaction parameters which include time, temperature, substrate molar ratio, and amount of enzyme. Reactions under optimized conditions has yielded a high percentage of esterification ( $>96 \%)$ for n-butanol, iso-butanol, and sec-butanol, indicating that extent of esterification is independent of the alcohol structure for primary and secondary alcohols at the optimum conditions. Minimum reaction time (135 min) for achieving maximum ester yield was obtained for iso-butanol. The required time for attaining maximum yield and also the initial rates in the synthesis of di-n-butyl and di-sec-butyl adipate were nearly the same. Immobilized Candida antarctica lipase B was also capable of esterifying tert-butanol with a maximum yield of $39.1 \%$. The enzyme is highly efficient biocatalyst for the synthesis of adipate esters by offering a simple production process and a high esterification yield.

\section{Introduction}

Natural and synthetic esters are essential materials in chemical industry. They have been most commonly applied in manufacturing of lubricating oils, solvents, plasticizers, paints, food, pharmaceuticals, cosmetics, and liquid fuels [1]. Among the esters, dicarboxylic acid esters are of particular interest due to their excellent properties such as low volatility, high flash point, good thermal stability, and low toxicity [2]. Up to now, the processes of esterification in industry are still catalyzed by chemical catalysts mainly sulfuric acid. However, difficulties in the recovery of catalyst, high energy consumption, corrosion of equipments, and the necessity for treatment of wastes are disadvantages in the chemically catalyzed synthesis [3]. In recent years, the use of enzymes for carrying out esterification reactions has been extensively studied. In comparison with chemical catalysts, enzymes show higher specificity and selectivity, they work in milder conditions, and they are more environmentally friendly [4]. Among the enzymes, Candida antarctica lipase B (CalB) has shown a high catalytic activity for esterification of dicarboxylic acids $[5,6]$. CalB is a versatile catalyst for a wide range of organic reactions [7]. Its high activity, thermostability, selectivity, and specificity compared to other known lipases make it special for unique applications [8].

In order to develop an efficient enzyme catalyzed process, knowledge of the substrate specificity is important [9]. The specificity of enzyme for different substrates cannot be predicted easily. Any factor that influences the enzyme-substrate binding or catalytic rate can affect the specificity of the enzyme [10]. So far, there are few studies on determining the substrate specificity of enzyme at the optimal value of all parameters influencing the reaction yield. Enzymatic synthesis of adipate esters using adipic acid and primary alcohols has been previously reported by $[11,12]$. Furthermore, specificity of the enzyme for primary alcohols with different 
chain lengths, in the synthesis of adipate esters, has been previously studied [13]. In this study, specificity of the enzyme for alcohols of different classes, namely, primary, secondary, and tertiary alcohols, is investigated.

In the present study, response surface methodology (RSM) was used to optimize the reaction conditions. RSM is a useful statistical technique for optimizing multiple variables to predict best performance conditions using minimum cost and number of experiments [14]. It is used as a tool to assess the effects of several independent factors on the dependent variables. RSM has successfully been applied to study and optimize the enzymatic synthesis of various esters $[15,16]$.

In the present work, response surface methodology was used for studying the substrate specificity of immobilized Candida antarctica lipase B in esterification of adipic acid with different butanols. The effects of several reaction parameters on the synthesis of adipate esters were evaluated. The optimum conditions were obtained, and the effect of alcohol structure on the optimum conditions was investigated.

\section{Materials and Methods}

2.1. Materials. Novozym 435 (specific activity $10000 \mathrm{PLU} / \mathrm{g}$; water content $1.4 \%$ ) was purchased from NOVO Nordisk A/S (Bagsvaerd, Denmark) and consists of Candida antarctica Lipase B (triacylglycerol hydrolase, EC 3.1.1.3) immobilized on the macroporous acrylic resin (poly [methyl methacrylate-co-butyl methacrylate]. Adipic acid, isobutanol (2-methylpropan-1-ol), sec-butanol, and tert-butanol (2-methyl-2-propanol) were purchased from Merck Co. (Darmstadt, Germany). n-Butanol was purchased from Sigma-Aldrich (St. Louis, MO, USA). All other chemicals and solvents used in this study were of analytical grade.

2.2. Lipase-Catalyzed Esterification. Different molar ratios of adipic acid and alcohol were mixed according to the experimental design, in $30 \mathrm{~mL}$ closed vials. Five milliliter of hexane was added as solvent [13]. Selection of hexane $(\log P=$ 3.5) as solvent was based on prior studies in which several solvents including hexane, heptane, acetone, ethyl acetate, butanol, and acetonitrile were screened for activity via lipase catalyzed esterification of adipic acid and different alcohols [17]. Different amounts of lipase, which were generated by RSM, were subsequently added. The reaction was performed in a temperature controlled (accuracy of $\pm 0.1^{\circ} \mathrm{C}$ ) horizontal water bath at $150 \mathrm{rpm}$ at different temperatures and for different time periods. The initial rates were calculated from the time profiles corresponding to the first minutes of the reaction (for which the profiles were approximately linear) and expressed as the amount of acid converted per unit of time per unit of weight of enzyme [18].

2.3. Analysis and Characterization. The reaction was terminated by dilution with $5 \mathrm{~mL}$ of ethanol: acetone $(50: 50 \mathrm{v} / \mathrm{v})$, and lipase was removed by filtration. Remaining free acid in the reaction mixture was determined by titration with $0.1 \mathrm{M}$
TABLE 1: Range of variables for the central composite design.

\begin{tabular}{lccccc}
\hline Variable & \multicolumn{5}{c}{ Levels } \\
& -1.682 & -1.000 & 0.000 & +1.000 & +1.682 \\
\hline Temperature, A $\left({ }^{\circ} \mathrm{C}\right)$ & 35.0 & 41.1 & 50.0 & 58.9 & 65.0 \\
Reaction time, B (min) & 30.0 & 109.0 & 225.0 & 340.9 & 420.0 \\
Enzyme amount, C (mg) & 20.0 & 97.0 & 210.0 & 323.0 & 400.0 \\
Substrate molar ratio, D & 1.0 & 2.4 & 4.5 & 6.6 & 8.0 \\
\hline
\end{tabular}

$\mathrm{NaOH}$ using phenolphthalein as the indicator. The moles of acid reacted were calculated from the values obtained for the control (without enzyme) and the test samples. The ester formed was expressed as equivalent to conversion of the acid [13]. Production of esters was characterized by FTIR spectroscopy with absorption bands of $\mathrm{C}=\mathrm{O}$ bend of ester at $1735,1732,1730$, and $1690 \mathrm{~cm}^{-1}$ for di-n-butyl, diiso-butyl, di-sec-butyl and di-tert-butyl adipate, respectively, and 1243,1162, 1164 and $1189 \mathrm{~cm}^{-1}$ for C-O stretching vibrations of di-n-butyl, di-iso-butyl, di-sec-butyl, and ditert-butyl adipate, respectively. Product was also monitored by gas chromatography/mass spectroscopy (GC/MS) on a Shimadzu (model GC 17A; model MS QP5050A; Shimadzu Corp, Tokyo, Japan) instrument with a BPX5 column $(0.25 \mathrm{~mm} \times 30 \mathrm{~mm}, 25$ micron $)$. According to GC/MS results, the reaction gave exclusive diester and formation of monoester was not observed. The mass spectrum of the products showed molecular ion at $m / z 258$ that corresponded to molecular formula $\mathrm{C}_{14} \mathrm{H}_{26} \mathrm{O}_{4}$. The two important ion peaks are related to the formation of ion asilium, $[\mathrm{RCO}]^{+}$, that gave the fragment ion at $\mathrm{m} / z 185$ (because of the loss of alkoxy group from the ester, $\mathrm{R}-\mathrm{O}$ ) and the fragment ion at $\mathrm{m} / z 129$ [O-CO- $\left.\left(\mathrm{CH}_{2}\right)_{4}-\mathrm{C}=\mathrm{OH}\right]^{+}$because of the rearrangement of the alkyl portion of the molecule. Other bonds cleavage occurred through some pathways and gave fragments ions at different $\mathrm{m} / \mathrm{z}$.

2.4. Experimental Design, Statistical Analysis, and Optimization. Response surface methodology (RSM) was applied to model the lipase catalyzed synthesis of adipate esters. To obtain a proper model for optimization, a four-factorfive-level central composite design (CCD) was employed, requiring 21 experiments. The fractional factorial design consisted of 8 factorial points, 8 axial points, and 5 center points. The variables and their levels selected for the adipate ester synthesis were temperature $\left(35^{\circ} \mathrm{C}-65^{\circ} \mathrm{C}\right)$, time $(30$ $420 \mathrm{~min})$, amount of enzyme $(20-400 \mathrm{mg})$, and substrate molar ratio (alcohol to adipic acid, $1: 1-8: 1$ ). The design of experiments employed is presented in Table 1. Selection of the variables and their levels was based on the results obtained in our preliminary studies using one variable at a time approach. The experiments were produced in random order, and triplicate measurements of esterification yield were run on each experiment.

A software package of Design Expert Version 7.1.1 (StateEase Inc., Statistics Made Easy, Minneapolis, MN, USA) was applied in this study. A second-order polynomial equation 
TABLE 2: The predictive response equations relating yield of esterification to process parameters.

\begin{tabular}{lc}
\hline Ester & Model in terms of coded factors \\
\hline Di-n-butyl adipate & $Y=+86.56+5.10 A+8.61 B+2.60 C+9.65 D-2.96 B^{2}-2.62 D^{2}$ \\
\hline $\begin{array}{l}\text { Di-iso-butyl adipate } \\
\text { Di-sec-butyl adipate }\end{array}$ & $Y=+94.80+2.92 A+10.66 B+3.00 C+12.30 D-5.31 B^{2}-7.74 D^{2}+1.72 A D-6.17 B D-2.63 C D$ \\
\hline $\begin{array}{l}\text { Di-tert-butyl } \\
\text { adipate }\end{array}$ & $Y=+90.31+4.83 A+9.96 B+1.98 C+12.93 D-3.46 B^{2}-6.72 D^{2}-4.44 B D$ \\
\hline
\end{tabular}

$Y$ is the percent yield; $A$ the temperature; $B$ the time; $C$ the amount of enzyme; $D$ the substrate molar ratio.

TABLE 3: The analysis of variance (ANOVA).

\begin{tabular}{|c|c|c|c|c|c|}
\hline Source & Sum of squares & Degree of freedom & Mean square & $F$-value & $P$ value \\
\hline \multicolumn{6}{|c|}{ Di-n-butyl adipate } \\
\hline Model & 2955.75 & 6 & 492.63 & 75.85 & $<0.0001$ \\
\hline Lack of fit & 61.65 & 10 & 6.17 & 0.84 & 0.6260 \\
\hline \multicolumn{6}{|l|}{$R^{2}=0.9702$} \\
\hline \multicolumn{6}{|c|}{ Di-iso-butyl adipate } \\
\hline Model & 5498.71 & 9 & 610.97 & 209.94 & $<0.0001$ \\
\hline Lack of fit & 29.12 & 7 & 4.16 & 5.75 & 0.0551 \\
\hline \multicolumn{6}{|l|}{$R^{2}=0.9942$} \\
\hline \multicolumn{6}{|c|}{ Di-sec-butyl adipate } \\
\hline Model & 5335.66 & 7 & 762.24 & 37.52 & $<0.0001$ \\
\hline Lack of fit & 244.27 & 9 & 27.14 & 5.47 & 0.0585 \\
\hline \multicolumn{6}{|l|}{$R^{2}=0.9528$} \\
\hline \multicolumn{6}{|c|}{ Di-tert-butyl adipate } \\
\hline Model & 764.28 & 9 & 84.92 & 48.26 & $<0.0001$ \\
\hline Lack of fit & 12.43 & 7 & 1.78 & 1.03 & 0.5221 \\
\hline$R^{2}=0.9753$ & & & & & \\
\hline
\end{tabular}

was developed to study the effects of the variables on the reaction yield

$$
y=b_{0}+\sum_{i=1}^{4} b_{i} x_{i}+\sum_{i=1}^{4} b_{i i} x_{i}^{2}+\sum_{i=j}^{3} \sum_{j=i+1}^{4} b_{i j} x_{i} x_{j}+e,
$$

where $y$ is the dependent variable (percentage of yield) to be modeled, $x_{i}$ and $x_{j}$ are the independent variables (factors), $b_{0}, b_{i}, b_{i i}$, and $b_{i j}$ are the regression coefficients of model and $e$ is the error of model. The fit of the model was evaluated by coefficient of determination $\left(R^{2}\right)$ and analysis of variance (ANOVA). The best-fitting model was determined by elimination of statistically insignificant terms until a significant model with an insignificant lack of fit was obtained.

\section{Results and Discussion}

Fitting of the data to various models (linear, two factorial, quadratic, and cubic) and their subsequent ANOVA showed that synthesis of adipate esters were most suitably described with quadratic polynomial model. The quadratic polynomial models for the synthesis of different adipate esters are shown in Table 2.
The ANOVA for response surface models has been shown in Table 3 . The very small $P$ value $(<0.0001)$ and a suitable coefficient of determination $\left(R^{2}\right.$ close to 1$)$ show that the quadratic polynomial models are highly significant and sufficient to present the actual relationship between the response and the variables. According to ANOVA, the "lack of fit" is not significant at $95 \%$ confidence level indicating that the generated models are satisfactory, with acceptable predictive power [14].

The analysis of variance indicated that all the independent variables were statistically significant for the synthesis of di-n-butyl and di-iso-butyl adipate. The amount of enzyme did not have a significant influence on the synthesis of disec-butyl adipate. Temperature and substrate molar ratio were also not significant factors for the synthesis of di-tertbutyl adipate. However, these insignificant factors were not eliminated from the model equations. In case of di-sec-butyl adipate, eliminating the amount of enzyme resulted in a significant lack of fit. If a model has a significant lack of fit, it is not a good predictor of the response and should not be used [19]. In case of di-tert-butyl adipate, although temperature and substrate molar ratio were not significant, their dependents (quadratic effects of temperature and substrate molar ratio, temperature $\times$ substrate molar ratio, and enzyme amount $\times$ substrate molar ratio interactions) were 


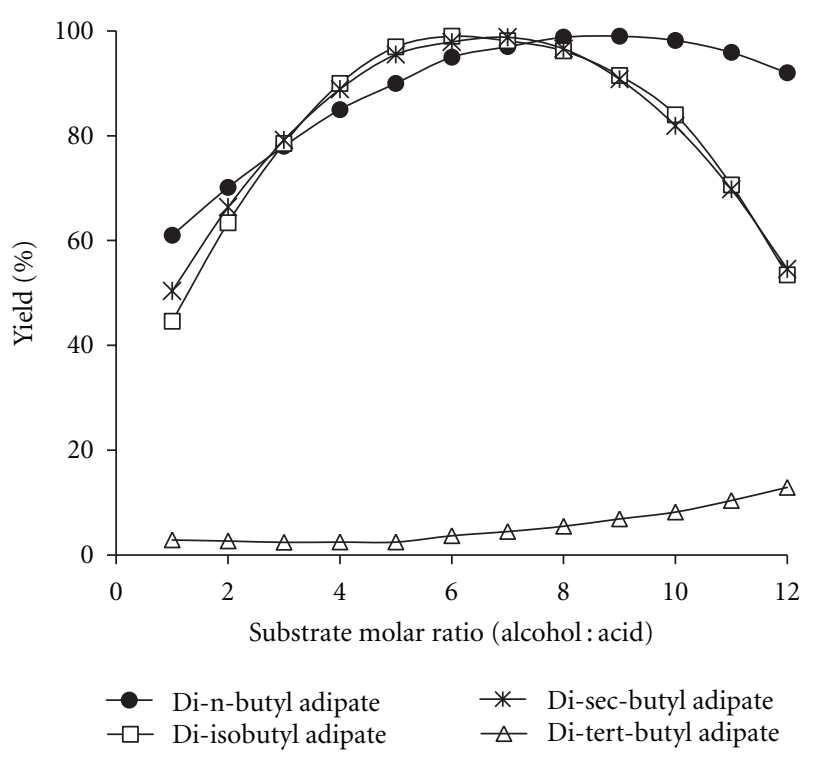

Figure 1: Effect of substrate molar ratio on the synthesis of adipate esters. Reaction conditions: temperature: $55^{\circ} \mathrm{C}$, time: $250 \mathrm{~min}$, and enzyme amount: $50 \mathrm{mg}$.

significant and can affect the response. When an interaction is included in the model, its parent terms must also be included, even if they do not appear to be significant on their own, to maintain the model hierarchy [20].

The equations shown in Table 2 were then used to study the effect of various parameters on the synthesis of adipate esters. Figure 1 shows the effect of varying substrate molar ratio on the reaction yields. For all the alcohols, the percentage yield increased with increasing substrate molar ratio up to a certain amount. As alcohol concentration was raised, the ester yield continuously decreased except for di-tert-butyl adipate. The result is obviously a consequence of substrate inhibition that leads to decrease in the enzyme activity [21]. Alcohol inhibition of the lipase B from Candida antarctica has been previously reported [10]. According to Zaidi et al. [22], reaction between alcohol and enzyme leads to blocking of the nucleophilic site of the enzyme that is involved in the acylation process. The results indicate that no inhibition by tert-butanol can be seen up to alcohol: acid molar ratio $12: 1$. In fact, due to the significant steric hindrance by the methyl groups in the proximity of the hydroxyl group, the nucleophilic attack by tert-butanol becomes increasingly difficult. Therefore, the reactivity of alcohol and also its corresponding inhibition is very low.

Figure 2 represents the time courses of the enzymatic synthesis of adipate esters at $55^{\circ} \mathrm{C}, 50 \mathrm{mg}$ enzyme and $4.5: 1$ substrate molar ratio. For all the esters except di-tert-butyl adipate, the percentage of yield increased with increase in incubation time up to an optimum amount. Prolonging the reaction time increases the volume of water produced by the reaction which leads to hydrolysis of ester [23]. Maximum production of di-tert-butyl adipate was observed within the first 30 minutes of the reaction. It can be concluded that time

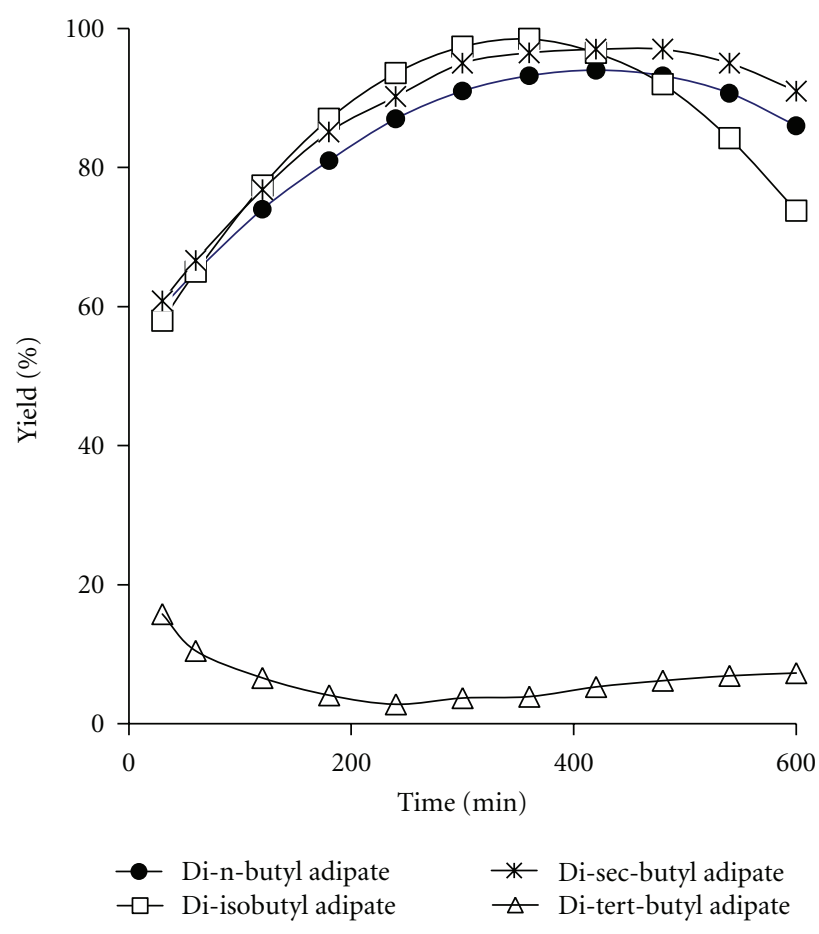

FIGURE 2: Time courses of adipate esters synthesis. Reaction conditions: temperature: $55^{\circ} \mathrm{C}$, enzyme amount: $50 \mathrm{mg}$, and substrate molar ratio: $4.5: 1$.

does not have a positive effect on the synthesis of di-tertbutyl adipate ester. This result also can be obtained from the predictive equation (Table 2) in which the factor of time has a negative coefficient.

Figure 3 shows the effects of reaction temperature on esterification of adipic acid with different butanols at substrate molar ratio $4.5: 1$, amount of enzyme $50 \mathrm{mg}$, and time $250 \mathrm{~min}$. The percentage of yields increased with increase in temperature within the given range $\left(35^{\circ} \mathrm{C}-65^{\circ} \mathrm{C}\right)$. Higher temperatures increase the kinetic energy of the system and hence collisions between enzyme and substrate molecules to result in accelerated rates of the reaction [24]. An increase in temperature also improves solubility of the substrates and reduces viscosity, and mass transfer limitations resulted in enhancement of the reaction yield. Due to the evaporation of the solvent (boiling point of n-hexane $=68^{\circ} \mathrm{C}$ ), higher temperatures were not considered for the reaction. Furthermore, high temperatures may also cause enzyme deactivation due to denaturation process. In the case of tert-butanol, by increasing the temperature, the reaction yield was only slightly increased, indicating that temperature is not a significant parameter in the synthesis of ester. This result is also confirmed by the ANOVA.

The effect of varying amount of enzyme on the esterification reaction at $250 \mathrm{~min}, 55^{\circ} \mathrm{C}$, and molar ratio of $4.5: 1$ is shown in Figure 4. An increase in enzyme concentration led to a marginal linear increase in esterification yield. Effect of enzyme amount seems to be more significant in the synthesis of di-tert-butyl adipate. According to ANOVA, F-value of the enzyme amount for the synthesis of di-tert-butyl adipate 


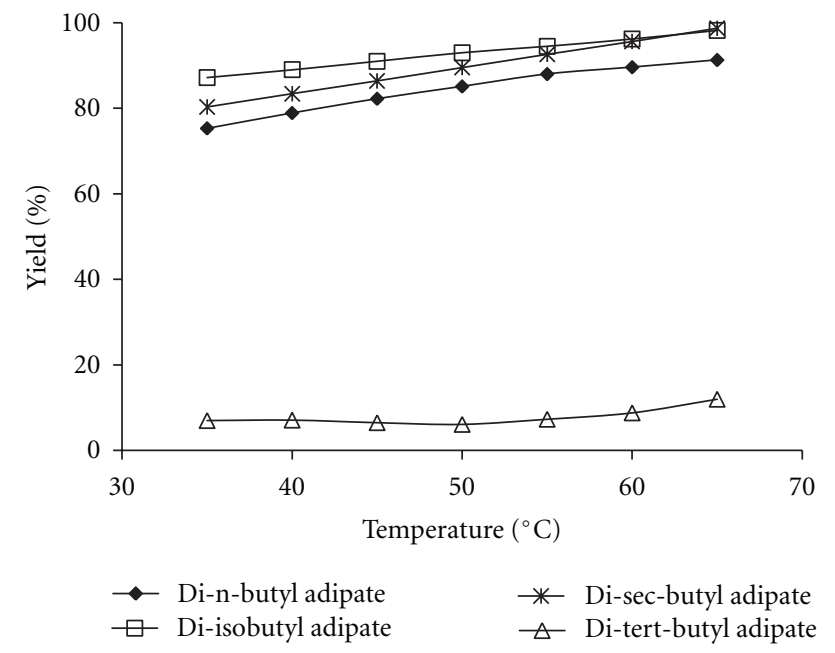

Figure 3: Effect of temperature on the synthesis of adipate esters. Reaction conditions: time: $250 \mathrm{~min}$, enzyme amount: $50 \mathrm{mg}$, and substrate molar ratio: $4.5: 1$.

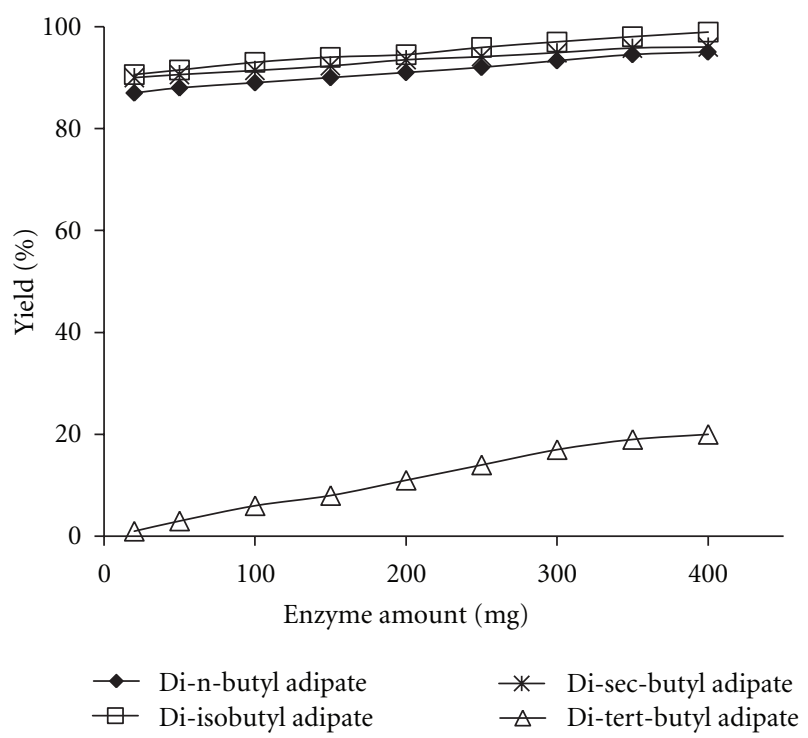

FIGURE 4: Effect of amount of enzyme on the synthesis of adipate esters. Reaction conditions: temperature: $55^{\circ} \mathrm{C}$, time: $250 \mathrm{~min}$, and substrate molar ratio: $4.5: 1$.

is 411.6, whereas for di-n-butyl, iso-butyl, and sec-butyl adipate, it is $14.4,50.8$, and 2.7 , respectively. The presence of larger amounts of enzyme provides more active sites for acyl-enzyme complex formation [24].

From an economic point of view, the most efficient conditions for the reactions would be to use the lowest amount of enzyme to achieve the highest yield of ester. The predicted maximum percentage of yield using minimum amount of enzyme was $100.0 \%$ for di-n-butyl, di-iso-butyl, and di-sec-butyl adipate (Table 4 ). A yield of $42.8 \%$ was also predicted for the synthesis of di-tert-butyl adipate. Validation experiments carried out under predicated conditions showed good correspondence between experimental and predicted values. The obtained results imply that the

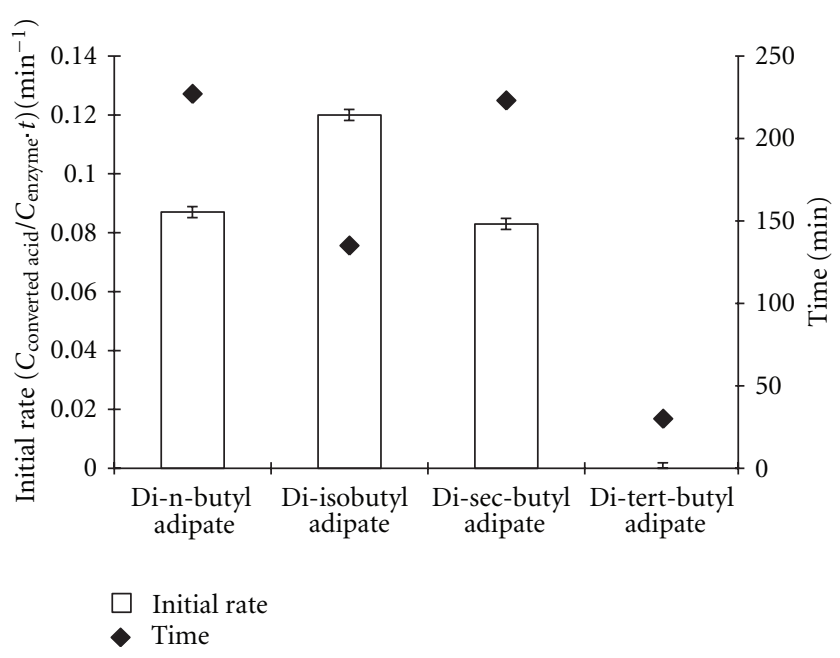

FIGURE 5: Effect of different classes of alcohols on the initial rate and minimum time required for maximum production of adipate esters. Reaction conditions: temperature: $62^{\circ} \mathrm{C}$, enzyme amount: $35 \mathrm{mg}$, and substrate molar ratio: $7.7: 1$.

maximum extent of esterification of adipic acid with primary and secondary alcohols is independent of the structure of alcohol.

Initial rates of the synthesis of adipate esters from different classes of alcohols are shown in Figure 5. Figure 5 also shows the required minimum time for maximum production of adipate esters at a reaction condition of $62^{\circ} \mathrm{C}, 35 \mathrm{mg}$ enzyme amount, and substrate molar ratio $7.7: 1$.

The highest initial rate $\left(0.12 \mathrm{~min}^{-1}\right)$ and shortest required time $(135 \mathrm{~min})$ were observed in the synthesis of diiso-butyl adipate. This result is similar to the earlier findings by Deng et al. [25] that respecting the type of butanols in alcoholysis of alkyl esters, iso-butanol was superior to n-butanol as a substrate for CalB. However, it should be pointed out that this superiority is in the required time for synthesis of the esters and the extent of esterification is the same for both the alcohols. The initial rates of synthesis of di-n-butyl and di-sec-butyl adipate and also their required minimum time for maximum ester production (100.0\%) were very similar. The result indicates that CalB has equal tendency for synthesis of these esters. The initial rate for the synthesis of tert-butyl adipate was nearly zero, and the maximum conversion yield (14.8\%) obtained in 30 minutes was very low compared to other esters. According to Kourist and Bornscheuer [26], most of the commercially available enzymes do not accept tertiary alcohols as substrates. It was proposed that the configuration of the oxyanion hole in the lipase having bulky hydrophobic residues prevents activity towards tertiary alcohols with bulky structure.

\section{Conclusion}

Optimization of several reaction parameters in Novozym 435-catalyzed esterification of adipic acid and different class of butanols was performed using response surface methodology. In this study, the specificity of the immobilized 
TABLE 4: Optimum conditions for lipase-catalyzed synthesis of adipate esters.

\begin{tabular}{lcccccc}
\hline Alcohol & $\begin{array}{c}\text { Temperature } \\
\left({ }^{\circ} \mathrm{C}\right)\end{array}$ & $\begin{array}{c}\text { Time } \\
(\mathrm{min})\end{array}$ & $\begin{array}{c}\text { Enzyme } \\
\text { amount }(\mathrm{mg})\end{array}$ & $\begin{array}{c}\text { Substrate } \\
\text { molar ratio }\end{array}$ & $\begin{array}{c}\text { Predicted } \\
\text { yield }(\%)\end{array}$ & $\begin{array}{c}\text { Actual } \\
\text { yield }(\%)\end{array}$ \\
\hline n-butanol & 56 & 268 & 35 & 7.7 & 6.0 & 100.0 \\
iso-butanol & 54 & 220 & 20 & 6.4 & 100.0 & 97.2 \\
sec-butanol & 55 & 264 & 35 & 3.8 & 100.0 & 96.0 \\
tert-butanol & 65 & 30 & 350 & & & 42.8 \\
\hline
\end{tabular}

Candida antarctica lipase B for alcohols of different classes in the esterification of a short chain dicarboxylic acid was determined. A high percentage of yield, 100.0\%, was predicted by the models for esterification of primary and secondary butanols implying that the maximum yield of esterification is independent of the alcohol structure for primary and secondary alcohols. Considering the substrate specificity behavior of the enzyme, structure of alcohol is an important parameter that can affect the optimized condition of other reaction parameters for the synthesis of adipate esters. The optimum conditions can also be used for future upscaling of the enzymatic production of adipate esters to obtain economically high-quality useful products at lower costs.

\section{References}

[1] S. Gryglewicz, M. Stankiewicz, F. A. Oko, and I. Surawska, "Esters of dicarboxylic acids as additives for lubricating oils," Tribology International, vol. 39, no. 6, pp. 560-564, 2006.

[2] S. Gryglewicz and F. A. Oko, "Dicarboxylic acid esters as components of modern synthetic oils," Industrial Lubrication and Tribology, vol. 57, no. 3, pp. 128-132, 2005.

[3] S. Demirkol, H. A. Aksoy, M. Tüter, G. Ustun, and D. A. Sasmaz, "Optimization of enzymatic methanolysis of soybean oil by response surface methodology," Journal of the American Oil Chemists'Society, vol. 83, no. 11, pp. 929-932, 2006.

[4] M. L. Foresti and M. L. Ferreira, "Solvent-free ethyl oleate synthesis mediated by lipase from Candida antarctica B adsorbed on polypropylene powder," Catalysis Today, vol. 107108, pp. 23-30, 2005.

[5] A. Mahapatro, A. Kumar, and R. A. Gross, "Mild, solvent-free $\omega$-hydroxy acid polycondensations catalyzed by Candida antarctica lipase B," Biomacromolecules, vol. 5, no. 1, pp. 6268, 2004.

[6] R. W. McCabe and A. Taylor, "An investigation of the acylbinding site of Candida antarctica lipase B," Enzyme and Microbial Technology, vol. 35, no. 5, pp. 393-398, 2004.

[7] B. Chen, J. Hu, E. M. Miller, W. Xie, M. Cai, and R. A. Gross, "Candida antarctica Lipase B chemically immobilized on epoxy-activated micro- and nanobeads: catalysts for polyester synthesis," Biomacromolecules, vol. 9, no. 2, pp. 463-471, 2008.

[8] P. Trodler and J. Pleiss, "Modeling structure and flexibility of Candida antarctica lipase B in organic solvents," BMC Structural Biology, vol. 8, pp. 9-18, 2008.

[9] L. Vaysse, A. Ly, G. Moulin, and E. Dubreucq, "Chain-length selectivity of various lipases during hydrolysis, esterification and alcoholysis in biphasic aqueous medium," Enzyme and Microbial Technology, vol. 31, no. 5, pp. 648-655, 2002.

[10] L. F. García-Alles and V. Gotor, "Alcohol inhibition and specificity studies of lipase B from Candida antarctica in organic solvents," Biotechnology and Bioengineering, vol. 59, no. 2, pp. 163-170, 1998.

[11] N. Chaibakhsh, M. B. Abdul Rahman, M. Basri, A. B. Salleh, and S. Abd-Aziz, "Lipase-catalyzed dimethyl adipate synthesis: response surface modeling and kinetics," Biotechnology Journal, vol. 5, no. 8, pp. 848-855, 2010.

[12] M. B. Abdul Rahman, N. Chaibakhsh, M. Basri, R. N. Z. R. A. Rahman, A. B. Salleh, and S. M. Radzi, "Modeling and optimization of lipase-catalyzed synthesis of dilauryl adipate ester by response surface methodology," Journal of Chemical Technology and Biotechnology, vol. 83, no. 11, pp. 1534-1540, 2008.

[13] N. Chaibakhsh, M. B. Abdul Rahman, M. Basri, A. B. Salleh, and R. N. Z. R. A. Rahman, "Effect of alcohol chain length on the optimum conditions for lipase-catalyzed synthesis of adipate esters," Biocatalysis and Biotransformation, vol. 27, no. 5-6, pp. 303-308, 2009.

[14] E. R. Gunawan, M. Basri, M. B. Abdul Rahman, A. B. Salleh, and R. N. Z. A. Rahman, "Study on response surface methodology (RSM) of lipase-catalyzed synthesis of palm-based wax ester," Enzyme and Microbial Technology, vol. 37, no. 7, pp. 739-744, 2005.

[15] P. S. Keng, M. Basri, M. B. Abdul Rahman, A. B. Salleh, R. N. Z. A. Rahman, and A. Ariff, "Optimization of palm based wax esters production using statistical experimenal designs," The Journal of Oleo Science, vol. 54, pp. 519-528, 2005.

[16] G. A. Macedo, G. M. Pastore, and M. I. Rodrigues, "Optimising the synthesis of isoamyl butyrate using Rhizopus sp. lipase with a central composite rotatable design," Process Biochemistry, vol. 39, no. 6, pp. 687-692, 2004.

[17] M. B. Abdul Rahman, U. H. Zaidan, M. Basri, M. Z. Hussein, R. N. Z. A. Rahman, and A. B. Salleh, "Enzymatic synthesis of methyl adipate ester using lipase from Candida rugosa immobilized on $\mathrm{Mg}, \mathrm{Zn}$ and $\mathrm{Ni}$ of layered double hydroxides (LDHs)," Journal of Molecular Catalysis B: Enzymatic, vol. 50, pp. 33-39, 2008.

[18] G. Trubiano, D. Borio, and A. Errazu, "Influence of the operating conditions and the external mass transfer limitations on the synthesis of fatty acid esters using a Candida antarctica lipase," Enzyme and Microbial Technology, vol. 40, no. 4, pp. 716-722, 2007.

[19] M. J. Anderson and P. J. Whitcomb, RSM Simplified: Optimizing Processes Using Response Surface Methods for Design of Experiments, vol. 264, Productivity Press, New York, NY, USA, 1st edition, 2005.

[20] J. Piexoto, "A property of well-formulated polynomial regression models," The American Statistician, vol. 44, pp. 26-30, 1990.

[21] D. L. Purich and R. D. Allison, Handbook of Biochemical Kinetics, vol. 661, Academic Press, New York, NY, USA, 1st edition, 2000.

[22] A. Zaidi, J. L. Gainer, G. Carta et al., "Esterification of fatty acids using nylon-immobilized lipase in n-hexane: kinetic 
parameters and chain-length effects," Journal of Biotechnology, vol. 93, no. 3, pp. 209-216, 2002.

[23] P. Villeneuve, B. Barea, P. Sarrazin et al., "Synthesis of pyroglutamic acid fatty esters through lipase-catalyzed esterification with medium chains alcohols," Enzyme and Microbial Technology, vol. 33, no. 1, pp. 79-84, 2003.

[24] E. L. Soo, A. B. Salleh, M. Basri, R. N. Z. A. Rahman, and K. Kamaruddin, "Response surface methodological study on lipase-catalyzed synthesis of amino acid surfactants," Process Biochemistry, vol. 39, no. 11, pp. 1511-1518, 2004.

[25] L. Deng, X. Xu, G. G. Haraldsson, T. Tan, and F. Wang, "Enzymatic production of alkyl esters through alcoholysis: a critical evaluation of lipases and alcohols," Journal of the American Oil Chemists' Society, vol. 82, no. 5, pp. 341-347, 2005.

[26] R. Kourist and U. T. Bornscheuer, "Biocatalytic synthesis of optically active tertiary alcohols," Applied Microbiology and Biotechnology, vol. 91, no. 3, pp. 505-517, 2011. 

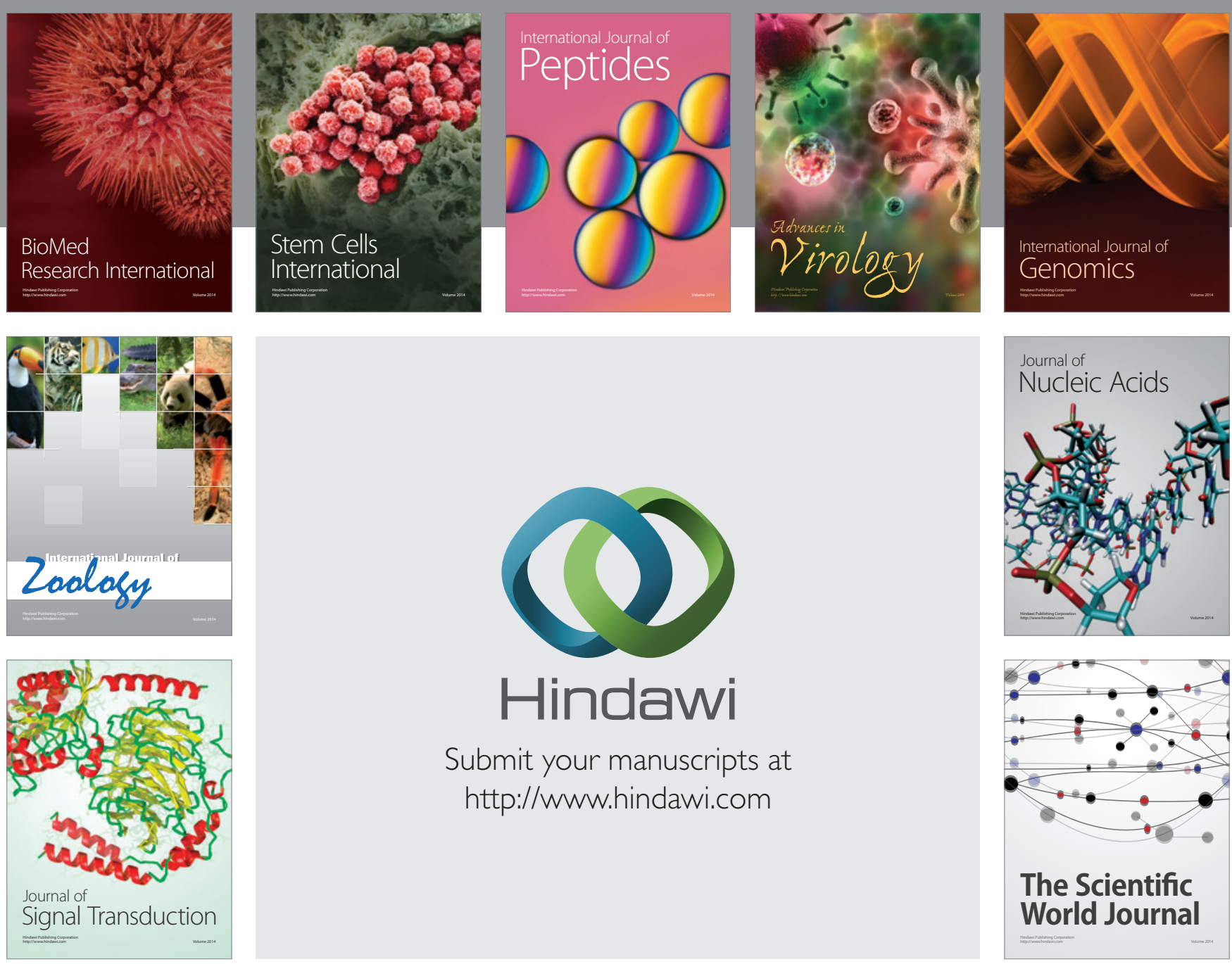

Submit your manuscripts at

http://www.hindawi.com
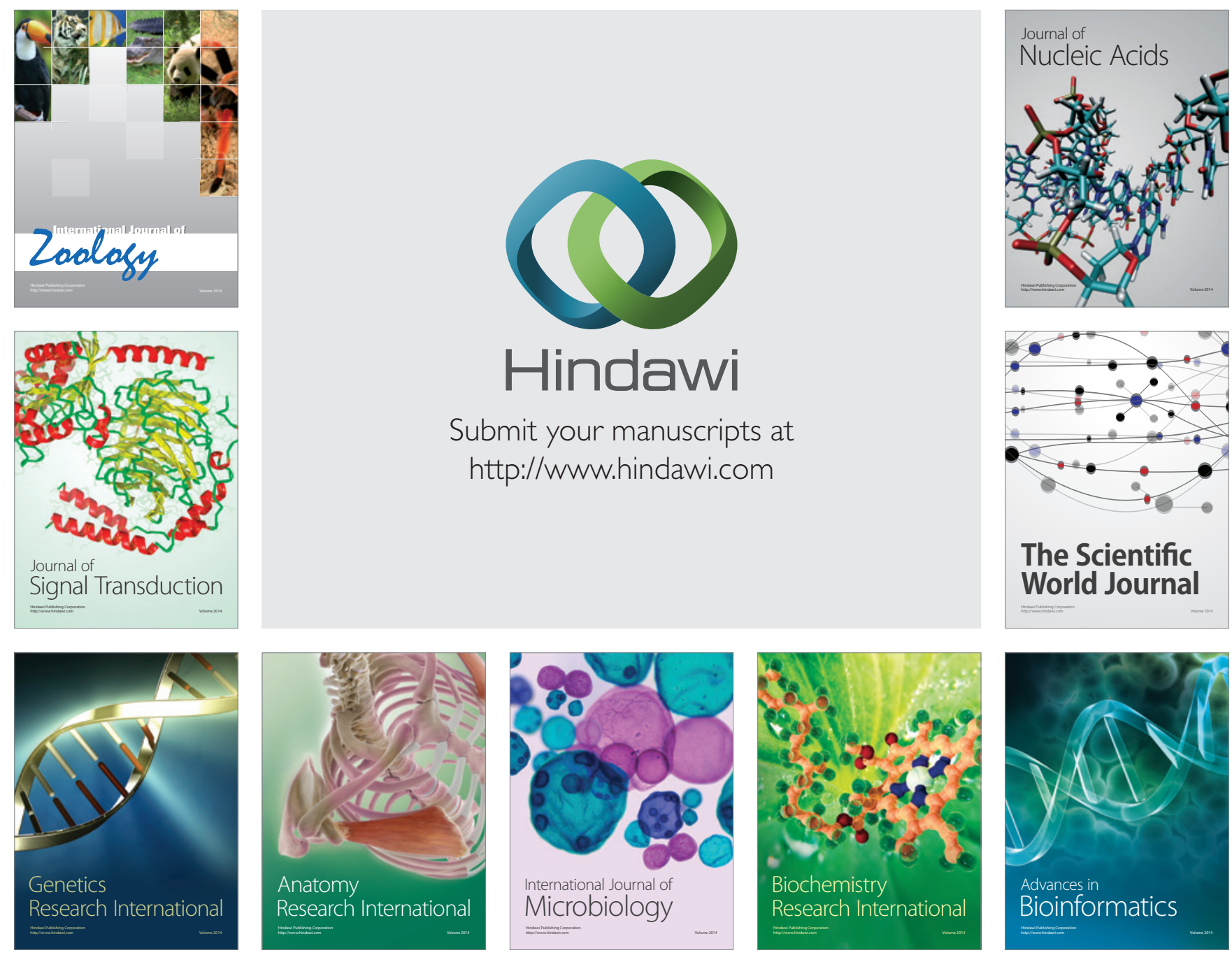

The Scientific World Journal
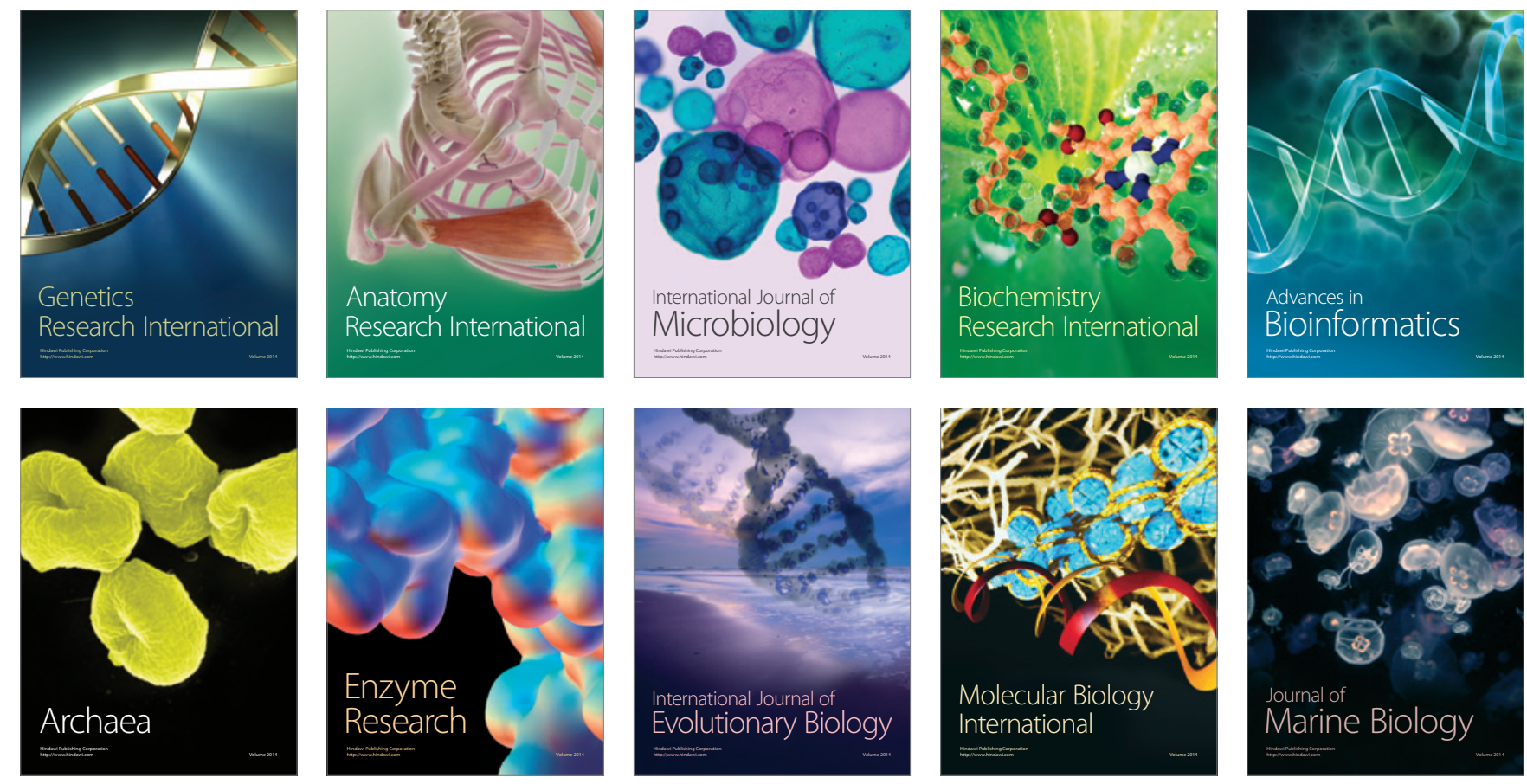